\title{
Myocardial infarction in a previously healthy middle age body builder
}

\section{Dean Strinić*, Jasna Čerkez Habek, Tea Blažević}

University Hospital "Sveti Duh", Zagreb, Croatia
RECEIVED:

January 31, 2018

ACCEPTED:

February 10, 2018

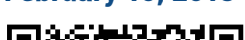

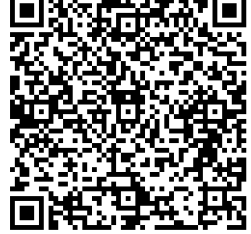

KEYWORDS: myocardial infarction, testosterone, stent thrombosis.

CITATION: Cardiol Croat. 2018;13(1-2):32. | https://doi.org/10.15836/ccar2018.32

*ADDRESS FOR CORRESPONDENCE: Dean Strinić, Klinička bolnica "Sveti Duh", Sveti Duh 64, HR-10000 Zagreb, Croatia. / Phone: +385-91-5345-973 / E-mail: destrinic@gmail.com

ORCID: Dean Strinić, https://orcid.org/0000-0001-6345-2037 • Jasna Čerkez Habek, https://orcid.org/0000-0003-3177-3797 Tea Blažević, https://orcid.org/0000-0003-3189-8661

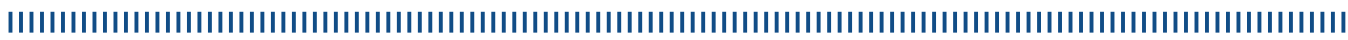

Introduction: Controversy exists regarding the safety of testosterone replacement therapy following recent report of an increased risk of adverse cardiovascular events. A total of 7 population-based studies analyzed the association between cardiovascular disease and levels of total testosterone. Although 3 of these studies found statistically significant higher cardiovascular mortality associated with lower levels of total testosterone, the others 4 studies did not confirm these results. In both medical and lay literature, one of the principal adverse effects generally associated with anabolic steroid use is the increased risk for myocardial infarction. However, direct evidence showing cause and effect between anabolic steroid administration and myocardial infarction is limited. Many of the case studies reported normal coronary arterial function in anabolic steroid users who experienced myocardial infarction, while others have shown occluded arteries with thrombus formation. ${ }^{1-3}$

Case report: 53-year-old male patient without standard risk factors for cardiovascular disease, had taken i.m. testosterone once a month during a period of 15 years and was admitted in August 2017 with ST-segment elevation myocardial infarction (STEMI) of the anteroseptal wall. Primary percutaneous coronary intervention (pPCI) of the proximal left anterior descending coronary artery (LAD) with implantation of the drug-eluting stent $(3.5 \times 18 \mathrm{~mm})$ was performed immediately. One hour later, patient had chest pain with ST-segment elevation localized in anteroseptal leads which was induced by early coronary stent thrombosis and rePCI of previously treated LAD was performed with an implantation of a second drug-eluting stent $(3.5 \times 15 \mathrm{~mm})$. One hour later, transitory ST-segment denivelation of the inferior wall was reported in ECG. Echocardiography showed non-dilated left ventricle with mild reduction in systolic function (EF 45\%) with hypokinesis of anterior wall and apex. Level of testosterone in patient was above reference value.

Conclusion: The use of testosterone with known coronary artery disease is yet controversial.

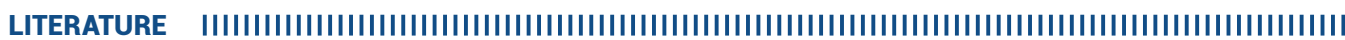

1. Budoff MJ, Ellenberg SS, Lewis CE, Mohler ER 3rd, Wenger NK, Bhasin S, et al. Testosterone Treatment and Coronary Artery Plaque Volume in Older Men With Low Testosterone. JAMA. 2017 Feb 21;317(7):708-716. https://doi.org/10.1001/jama.2016.21043

2. Anderson JL, May HT, Lappé DL, Bair T, Le V, Carlquist JF, et al. Impact of Testosterone Replacement Therapy on Myocardial Infarction, Stroke, and Death in Men With Low Testosterone Concentrations in an Integrated Health Care System. Am J Cardiol. 2016 Mar 1;117(5):794-9. https://doi.org/10.1016/j.amjcard.2015.11.063

3. Akishita M, Hashimoto M, Ohike $\mathrm{Y}, 0$ gawa S, lijima K, Eto M, et al. Low testosterone level as a predictor of cardiovascular events in Japanese men with coronary risk factors. Atherosclerosis. 2010 May;210(1):232-6. https://doi.org/10.1016/j.atherosclerosis.2009.10.037 